\title{
The Effects of Very Low Energy Diets and Low Energy Diets with Exercise Training on Skeletal Muscle Mass: A Narrative Review
}

\author{
Arash Ardavani · Hariz Aziz • Ken Smith • Philip J. Atherton • \\ Bethan E. Phillips · Iskandar Idris
}

Received: September 10, 2020 / Accepted: November 4, 2020 / Published online: November 19, 2020

(C) The Author(s) 2020

\begin{abstract}
In recent years, very-low-energy diets (VLEDs) have been recognised as a viable strategy for improving the extent of weight loss and cardiometabolic outcomes in people who are either overweight or obese. However, concerns exist regarding the reductions in lean body mass (LBM) during VLEDs, particularly in vulnerable demographic groups, such as middle-aged and older adults already prone to developing sarcopenia. Sarcopenia is itself associated with multiple adverse outcomes, including frailty, cardio-metabolic deterioration and increased
\end{abstract}

A. Ardavani - H. Aziz - K. Smith - P. J. Atherton ·

B. E. Phillips · I. Idris $(\varangle)$

Clinical, Metabolic and Molecular Physiology Research Group, MRC-Versus Arthritis Centre for Musculoskeletal Ageing Research, University of Nottingham, Royal Derby Hospital Centre, Derby, UK

e-mail: iskandar.idris@nottingham.ac.uk

A. Ardavani · H. Aziz - K. Smith - P. J. Atherton ·

B. E. Phillips · I. Idris

National Institute for Health Research (NIHR)

Nottingham Biomedical Research Centre,

Nottingham, UK mortality. Therefore, a number of studies investigating strategies to ameliorate this detrimental effect of VLEDs have attempted to address this concern. This narrative review explores the potential benefits and limitations of exercise and/or protein supplementation for LBM retention during VLEDs based on the available evidence. Current studies suggest that both protein supplementation and exercise training may result in improved LBM retention (and skeletal muscle function) during VLEDs. However, uncertainty remains concerning the interactions between intervention types, based on discordant outcomes reported in the literature and the heterogeneity of exercise modalities in achieving this particular outcome.

Keywords: High-intensity interval training; Resistance exercise training; Sarcopenia; Skeletal muscle; Very-low-calorie diet 


\section{Key Summary Points}

What is already known?

Very low-energy diets (VLEDs) have been implemented successfully primarily as a means of improving body composition, but also to improve metabolic parameters.

However, as a consequence of profound energy restriction, VLEDs are associated with reductions in lean body mass (LBM).

Theoretically, additional protein in LEDs will result in enhanced retention of LBM.

Based on distinct physiological adaptation, differing forms of exercise will likely exert different effects on lean body mass retention during LEDs.

\section{What are the new findings?}

Resistance exercise training (RET) may significantly improve LBM retention during LEDs, although the precise effect and magnitude are unclear.

The reported effects of aerobic exercise training (AET) on LBM preservation during LEDs are conflicting.

Currently, there are insufficient data to report the effect of high-intensity interval training (HIIT) on LBM retention during LEDs.

There are also inadequate data to discern the effect of additional dietary protein during LEDs with exercise.

\section{DIGITAL FEATURES}

This article is published with digital features, including a summary slide, to facilitate understanding of the article. To view digital features for this article go to https://doi.org/10.6084/ m9.figshare.13187495.

\section{VERY-LOW-ENERGY DIETS}

\section{An Introduction to Very-Low-Energy Diets}

Very low energy diets (VLEDs) are defined as any diet that consists of $<3347$ kilojoules (kJ) per day $(800 \mathrm{kcal} /$ day $)$, with a modified macronutrient and specified micronutrient composition (Table 1) [1, 2]. Modern VLEDs comprise $2510 \mathrm{~kJ}$ per day $(600 \mathrm{kcal} /$ day $)$ through commercially available meal replacement items, with any remaining intake typically consumed at the discretion of the patient [1]. Low-energy diets (LEDs) consist of 3347 to $5021 \mathrm{~kJ} /$ day (800 to $1200 \mathrm{kcal} /$ day) [2]. The observed rate of weight loss in VLEDs and LEDs in multiple studies is up to $2.5 \mathrm{~kg}(\mathrm{~kg})$ per week during the first 4 to 6 weeks of intervention [2]. However, in longer term intervention trials where VLEDs were trialled for up to 6 months, the rate of weight loss was reduced to approximately $0.8 \mathrm{~kg}$ per week after the first 6 weeks and was maintained thereafter [2]. In our previous systematic review, which included six VLED studies [3], it was determined that the extent of weight loss ranged from 4.1 to $24 \mathrm{~kg}$ (average loss of $13.2 \mathrm{~kg}$ ) over an intervention period of between 5 days and 6 months [3]. However, the extent of weight regain after VLED cessation was observed to be between 2 to $14 \mathrm{~kg}$ in the post-intervention assessment

Table 1 Comparison of different (very)-low-energy diets [(V)LEDs] with respect to the extent of fat or lean body mass (LBM) loss that is observed ( adapted from Willoughby et al. 2018 [55])

\begin{tabular}{llll}
\hline Diet type & $\begin{array}{l}\text { Fat mass } \\
\text { loss }(\%)\end{array}$ & $\begin{array}{l}\text { LBM loss } \\
(\%)\end{array}$ & $\begin{array}{l}\text { Fat:LBM } \\
\text { loss ratio }\end{array}$ \\
\hline VLED & 75 & 25 & 3.0 \\
Low & 76 & 24 & 3.2 \\
$\quad$ carbohydrate & & & \\
Low fat & 76 & 24 & 3.2 \\
High protein & 89 & 11 & 8.1 \\
High fibre & 75 & 25 & 3.0 \\
\hline
\end{tabular}


period, which lasted between 8 days to 5 years [3]. Importantly, it is also recognised that approximately $25 \%$ of total weight loss with LEDs is associated with loss of lean body mass (LBM) (Table 1), which exhibits a direct and proportional relationship with the extent of net negative energy balance [4, 5]. As a result, VLEDs that elicit a profound energy deficit will result in a greater proportion of LBM reductions. LBM was determined in several studies by either the use of dual-energy x-ray absorptiometry (DEXA), or measuring the total body potassium content, based on the presumption that the potassium content of muscle is $68.1 \mathrm{mmol} / \mathrm{kg}[6,7]$.

\section{VLEDs and Cardiometabolic Improvements}

VLEDs have attracted attention in recent years due to improvements in type 2 diabetes mellitus (T2DM) assessment markers, as demonstrated by reductions in glycated haemoglobin (HbA1c), blood pressure (BP) and mean weight loss $[3,5,8-10]$. Furthermore, at least three studies have demonstrated that in insulin-dependent T2DM patients, a reduction in their insulin administration is observed following VLED interventions [3].

The Primary Care-led weight management for remission of T2DM (DiRECT) study, a multicentre randomised-control trial (RCT) with 306 participants across 49 sites, commenced in 2017 [11]. This study demonstrated that VLED resulted in an observed remission of T2DM (defined as HbA1c $<6.5 \%$ after withdrawal of all antidiabetic medications for at least 2 months) in $46 \%$ of participants in the intervention cohort following 1 year of intervention compared with only $4 \%$ in the control group (OR 19.7, 95\% Confidence Interval (CI) 7.8-49.8) [11]. In the 2nd year of intervention, 116 and 140 participants were included in the intervention and control groups, respectively [12]; $11.4 \%$ of participants experienced a weight loss $>15 \mathrm{~kg}$ in the intervention group compared with $2 \%$ in the control group (adjusted odds ratio 8.2 [95\% CI 2.2-30.0], $p=0.002$ ) [12]. However, no further delineation of weight type between fat and fat-free, or associated indicators of muscle strength or function, was assessed [12]. In summary, the DiRECT study provided direct evidence of T2DM remission via VLED with an associated loss of weight, although the proportion of patients experiencing these benefits was less following the first year of intervention.

\section{Safety Profile of VLEDs}

Although early VLED strategies were recognised as an effective way of achieving weight loss and the associated benefits, concerns were raised regarding the high incidence of sudden death following VLEDs. This was attributed to cardiac arrhythmias, which were ostensibly secondary to cardiac atrophy [3, 13]. Later studies investigating VLEDs incorporated meals containing a higher proportion of high-quality protein sources, ameliorating the previously suspected detrimental effect of VLEDs on cardiac health [3]. In support of this, a recent systematic review [3] on VLEDs found that no major adverse events were reported, with the exception of one study, which recorded a non-fatal myocardial infarction in both the control and VLED groups [4]. Furthermore, no incidences of cardiac arrhythmias, changes in PR interval or abnormal QRS complexes were reported [4].

\section{The Current Application of VLEDs}

Within the UK, the National Institute for Health and Clinical Excellence (NICE) endorses VLEDs for up to 3 months under supervised conditions in either those patients who fail to meet a target weight loss with a standard dietary approach or those who require rapid weight loss [8]. In addition, recent guidelines from the American Diabetes Association-European Association for the Study of Diabetes (ADA-EASD) also recommend the use of VLEDs for between 3 to 5 months followed by the gradual reintroduction of a normal diet [9]. A summary of some key considerations for clinicians intending to commence a VLED for their patients is provided in Table 2. 
Table 2 Key recommendations for clinicians advising patients undertaking very-low-energy diets (VLEDs)

Compliance-Continued adherence to a VLED may prove difficult for some patients who elect to trial a VLED.

Frameworks that facilitate sufficient compliance with the intervention should be strongly considered prior to its implementation. This may include diet personalisation to optimise adherence, reduce hunger or provide selfmonitoring [91]

Symptomology - Patients should be adequately counselled before commencing the diet with respect to the common symptoms. These may include fatigue, bloating, cold intolerance, constipation, haemorrhoid formation and dizziness. Development of these symptoms would require reporting to the responsible clinician [92]

Cholelithiasis susceptibility-Dietary composition may contribute to cholelithiasis formation [92]. This may be reduced by a proportional increase in fat content, relative to other macronutrients [93]

Mitigation of weight regain-VLEDs and LEDs are both associated with weight regain following the intervention period [92]. This may be addressed in part by counselling with respect to other lifestyle factors that contribute to weight loss maintenance [94]

\section{SKELETAL MUSCLE: MAINTENANCE AND METABOLIC FUNCTIONS}

\section{A Summary of Skeletal Muscle Homeostasis}

The skeletal muscle is the largest organ in the human body and constitutes between 30 and $40 \%$ of total body weight [14]. Maintenance of muscle mass relies on a dynamic equilibrium between muscle protein synthesis (MPS) and muscle protein breakdown (MPB) [15], with the external influences on skeletal muscle being physical activity and nutrition [16, 17]. Nutritional deficiency states that result in muscle wasting, such as anorexia, inflammation and cachexia, exemplify the importance of maintaining optimal anabolic responses through nutrition. Similarly, habitual physical activity is also required to maintain muscle mass; this has been demonstrated in multiple studies, evidenced by the observation that reduced physical activity results in an acceleration in LBM reduction [16, 18, 19]. This initial event may result in a reduced propensity towards physical activity, thus initiating an adverse negative feedback loop [20]. The molecular regulation of MPS and MPB is both complex and beyond the remit of this review, but does involve the protein kinase B (AKT)-mammalian target of rapamycin (mTOR) signalling cascade [21-27], which is influenced by both amino acid (AA) and glucose availability [25-27]. Our previous meta-analysis also concluded that insulin has a permissive role in MPS in the presence of elevated AAs and plays a major role in reducing MPB independent of AA availability [28], with the ubiquitin-proteasome system the main pathway for MPB [27-33]. The mechanistic pathways that modulate skeletal muscle provide researchers and clinicians with an understanding of the role through which VLEDs and adjunct interventions may affect this homeostatic process.

\section{Metabolic Role of Skeletal Muscle}

In addition to the recognised role of skeletal muscle in facilitating locomotion, posture and strength, it is also implicated in numerous metabolic processes essential for overall health [34-36]. Skeletal muscle serves as the largest reserve of protein in the body, permitting it to serve as an energy reserve during energy restriction and providing critical organs with AAs in times of infection and disease [37]. As the primary site of both insulin-dependent and -independent glucose disposal, skeletal muscle is especially important in the context of metabolic diseases-in particular, T2DM and obesity $[38,39]$. Skeletal muscle is a tissue that has been epidemiologically linked to global human 
health. Low skeletal muscle mass and subsequent low function (such as grip strength) have been linked to mortality, frailty and increased insulin resistance, with the latter being an important risk factor for adverse cardiovascular outcomes and metabolic dysfunction [4, 39].

\section{Skeletal Muscle and Sarcopenia}

Despite the crucial roles of skeletal muscle outlined above, some degree of muscle atrophy is inevitable (yet partially modifiable) with advancing age, a phenomenon known as sarcopenia $[40,41]$. This incipient condition begins at the age of approximately 40 years and occurs at a rate of approximately $0.5-1 \%$ skeletal muscle mass loss per year until the 7 th decade of life, where rates of muscle loss and therefore function substantially increase and decrease, respectively.[27]. Nutrition is essential for regulating muscle mass and function, whereby mitigating skeletal muscle atrophy whilst on a VLED is particularly important for middle-aged and older adults who are either pre-sarcopenic or are already suffering from clinically-defined sarcopenia. There are several objective metrics available used in the diagnosis of sarcopenia, which include grip strength for skeletal muscle strength, appendicular skeletal muscle mass (ASM) by DEXA for evaluating muscle quantity, ultrasound for muscle quality and short physical performance battery (SPPB) to assess physical performance (Table 3) [41]. Diagnosis of sarcopenia is confirmed where there is low muscle strength and low muscle quantity or quality [41].

\section{IMPACT OF PROTEIN ON LBM RETENTION IN VLEDS}

Dietary protein is widely recognised within the literature as the macronutrient with the most beneficial effects on LBM retention [42]. The National Health Service (NHS) currently recommends the average daily consumption of protein for adult men and women to be approximately $55 \mathrm{~g}$ and $45 \mathrm{~g}$ per day, respectively [43]. This recommendation aligns with that advocated in the United States of America (USA) [44]. In healthy athletes, the additional physical demands result in a recommended higher daily intake, with $1.3-1.8 \mathrm{~g} / \mathrm{kg} /$ day and $1.8-2.0 \mathrm{~g} / \mathrm{kg} /$ day being advocated for newer athletes or those in an energy deficit aiming to preserve LBM, respectively [44]. The overall effect of protein supplementation on physical strength and LBM in this particular demographic appears to be minor, where a leucinebased threshold of $2 \mathrm{~g}$ per instance of supplementation is also shown to exist [45].

Table 3 The European Working Group on Sarcopenia in Older People 2 (EWGSOP2) sarcopenia cut-off values ( adapted from Cruz-Jentoft et al. 2019 [41])

\begin{tabular}{lll}
\hline Test & Cut-off point for men & Cut-off point for women \\
\hline Grip strength & $<27 \mathrm{~kg}$ & $<16 \mathrm{~kg}$ \\
Chair stand & $>15 \mathrm{~s}$ for five rises & N $/ \mathrm{A}$ \\
ASM & $<20 \mathrm{~kg}$ & $<15 \mathrm{~kg}$ \\
ASM $/$ height $^{2}$ & $<7.0 \mathrm{~kg} / \mathrm{m}^{2}$ & $<5.5 \mathrm{~kg} / \mathrm{m}^{2}$ \\
Gait speed & $\leq 0.8 \mathrm{~m} / \mathrm{s}$ & N/A \\
SPPB & $\leq 8$ point score & $\leq 8$ point score \\
Timed up-and-go test (TUG) & $\geq 20 \mathrm{~s}$ & $\geq 20 \mathrm{~s}$ \\
$400-\mathrm{m}$ walk test & Non-completion or $\geq 6$ min for & Non-completion or $\geq 6 \mathrm{~min}$ for \\
& completion & completion \\
\hline
\end{tabular}


However, these guidelines are inappropriate for the sarcopenic individual [46, 47], given their differing physiological milieu. Although the USA Food and Nutrition Board recommends a daily Acceptable Macronutrient Distribution Range (AMDR) of $10-35 \%$ for protein (corresponding to $0.8-3.0 \mathrm{~g} / \mathrm{kg} /$ day) [46], the majority of elderly adults do not maintain a daily protein intake that lies within the upper bound of this range [47]. Consequently, the Society for Sarcopenia, Cachexia, and Wasting Disease have advocated the supplementation of the BCAA leucine to mitigate this [47]. Alternatively, it has been repeatedly observed that a general increase in dietary protein beyond the RDA increases MPS in sarcopenic individuals $[47,48]$. The impact of dietary protein timing across a $24 \mathrm{~h}$ duration has been investigated, but yields contradictory results in the literature at present $[45,48,49]$.

The potential adverse effects of chronic dietary protein supplementation beyond the stipulated RDA values or ranges has been a point of contention within the literature due to a paucity in longitudinal studies [50]. Within a short-term (8-week) intervention period, Antonio et al. (2016) performed a randomised crossover trial in resistance-trained healthy young men with either baseline or very high $(>3 \mathrm{~g} / \mathrm{kg} /$ day) protein diets and concluded that no adverse effects on biochemical markers assessing multiple organ systems were apparent [51]. Although this observation has been noted in other trials [51], the long-term effects remain unknown, with differing protein sources tentatively demonstrating differential effects on renal health [52]. Furthermore, higher protein supplementation results in an acceleration of renal impairment in patients following a myocardial infarction [53]. In addition, concerns also exist concerning a potential adverse association among higher protein supplementation and bone metabolism, coronary heart disease and liver function [54]. As such, although additional protein supplementation has an evidence base that suggests some protective effect for LBM preservation in sarcopenic patients, the utilisation of this strategy should be patient-tailored and past medical history or susceptibility to renal or bone metabolism abnormalities should be considered [53, 54].

Within the context of energy restriction, numerous studies have demonstrated that an increase in dietary protein in a LED state results in superior LBM retention (Table 1). Furthermore, an increase of dietary protein to between $1.7-2.3 \mathrm{~g} / \mathrm{kg} /$ day has been shown to result in improvements in LBM retention $[56,57]$.

The current evidence concerning the effects of additional protein supplementation in the context of VLED has to date yielded conflicting results. In 2018, Larsen et al. conducted an RCT assessing the effects of additional daily protein supplementation $(0.4 \mathrm{~g} / \mathrm{kg} / \mathrm{day})$ with $30 \mathrm{~min}$ of aerobic exercise training (AET) five times per week in 29 patients aged between 18 to 55 years who were either overweight or obese over a 4-week duration [58]. The authors of this study noted no statistically significant improvements in LBM retention during this period between the protein supplementation and placebo groups [58]. In contrast to these findings, Johansson et al. (2017) performed a systematic review and meta-analysis of 27 RCT studies, where 6 of these studies had intervention arms that utilised a high protein intervention with a total sample size of 865 [59]. Following pooled analysis of these studies, it was determined that a higher protein intake was associated with a larger effect size with respect to weight loss maintenance post-intervention $(1.5 \mathrm{~kg}$ mean, 95\% CI 0.8-2.1 kg; $p<0.001$ ) [59]. This finding may be an indirect indicator of greater LBM retention, secondary to the additional energy expenditure afforded by the recognised metabolic activity of skeletal muscle tissue [60]. Further replication of this finding has not been achieved at the current time.

\section{IMPACT OF EXERCISE ON LBM RETENTION IN VLEDS}

Exercise can be conceptually defined as an organised form of physical activity that provides both frequent exposure to a particular modality and a recoverable form of progression from the structured adaptation [61]. Traditionally, exercise was divided into two distinct 
categories: (1) resistance (RET) and (2) aerobic (or endurance) (AET) exercise training, with each conferring different benefits on human health [62]. RET is most commonly associated with muscle hypertrophy and an increase in physical strength, whereas AET is typically performed to improve cardiorespiratory fitness [36, 63-65].

\section{RET and LBM Retention in Low-Energy States}

RET is a known potent stimulator of MPS leading to muscle protein accretion and subsequent gains of muscle mass [65]. Multiple studies have demonstrated that MPS may be preferentially obtained through the manipulation of certain RET variables, including intensity and volume $[66,67]$. Incorporation of RET while in an energy restricted state has been shown to reduce the proportion of LBM losses from 25\% to approximately $17 \%[68,69]$, with increases in intensity and volume of RET shown to further enhance LBM retention [70].

Svensden et al. (1994) assessed the effects of RET combined with AET during energy restriction versus diet only and controls in an RCT of 21 post-menopausal women between 50 to 65 years old with obesity [71]. Although both the diet-only and the diet-plus-exercise groups lost comparable mean weight (approximately $8 \mathrm{~kg}$ ) by 24 weeks post-intervention, it was observed that only the RET-containing intervention arm demonstrated near-complete preservation of LBM [71]. In another randomised study, Donnelly et al. (1993) investigated the effects of RET in women with obesity (average ages $36.3 \pm 8.9$ and $44.4 \pm 9.8$ years for the control and intervention groups, respectively) during a 90-day LED of $3360 \mathrm{~kJ} /$ day (803 kcal/day) intervention period [72]. Their results demonstrated that the group that received RET in addition to LED showed an improvement of $10-17 \%$ in musculoskeletal strength, associated with skeletal muscle hypertrophy of both type I and II cross-sectional muscle fibre, relative to the group that received LED alone. Importantly, weight loss was similar across the groups (due to equivalent calorie deficit), but the composition of weight loss changed between groups [72]. Contrastingly, a more recent study by Brochu et al. (2009) performed a 6-month RCT in 107 women with overweight status and an average age range of 57.2-58 years, comparing an energy restriction diet-only and diet-plus-RET intervention arms [6]. The authors concluded that no statistically significant differences in LBM losses were observed between the arms, with significant losses in both $(-0.9 \pm 2.4 \mathrm{~kg}$ and $-0.4 \pm 2.2 \mathrm{~kg}$, respectively) [6]. The discrepancy is likely attributed to differences in the RET and LED regimes being utilised in these studies. The reduction of muscle strength as a result of LED was highlighted in a cohort study by Krotkiewski et al. (1990), where 32 women with obesity and an average age of $19 \pm 4$ years underwent a 4-week high-protein VLED intervention and reported decreases in isokinetic strength [7]. Specifically, these results revealed a progressive reduction in isokinetic knee extension strength [7]. However, the participants in this study did exhibit an increase in musculoskeletal isokinetic endurance post-intervention, despite showing an anticipated depreciation in glycogen concentration [7].

Ethnic-specific differences in LBM retention between VLED-only and VLED with RET interventions were noted by Hunter et al. (2018), who performed an RCT with 140 women with obesity between the ages of 20-44 years stratified based on age, pre-intervention BMI and ethnicity (African-American and EuropeanAmerican) [73]. It was discovered that the European-American participants had a statistically significant $(p<0.01)$ reduction in relative skeletal muscle mass index (RSMI) relative to the African-American participants in the diet-only group $\left(-0.24\right.$ versus $+0.08 \mathrm{~kg} / \mathrm{m}^{2}$, respectively) [73]. They observed changes with a VLED diet and RET $(+0.01$ versus $+0.10 \mathrm{~kg} /$ $\mathrm{m}^{2}$, respectively), but this result was not statistically significant $(p>0.20)$ [73]. Nonetheless, the difference in the diet-only intervention arm highlights the putative role of ethnicity (ostensibly serving as a proxy for genetic differences) in the response to diet or energy balance interventions. 


\section{AET and LBM Retention in Low-Energy States}

As with RET, the effect of combining VLED with AET has yielded contradictory results to date. In 1990, Hemysfield et al. conducted a 6-week RCT assessing the body composition and metabolic outcomes of 12 women between the ages of 25-45 years with obesity and discovered that the AET group, which consisted of a progressively increasing exercise volume (up to $5.6 \mathrm{~km}$ of walking), observed less reduction in LBM relative to the controls (AET group: $-2.2 \pm 0.8 \mathrm{~kg}$, control group: $2.6 \pm 0.6 \mathrm{~kg}$, $p<0.001)$ [74].

It is noteworthy that the overall proportion of total to LBM weight loss observed in this study's cohort was approximately 2:1 [74], reflecting a more pronounced reduction in LBM relative to conventional data pertaining to VLED-only (Table 1) or VLED paired with RET intervention strategies.

An additional, separate non-randomised interventional study (Hill et al. 1987) investigated the interaction of VLED with AET in eight women with obesity during a 5-week intervention period [75]. The authors of this study concluded that despite similar total weight loss between the two groups (VLED alone as control), the VLED-plus-AET group lost more fat mass than the diet alone group [75].

The above findings were not however observed in another non-randomised interventional study published in 1988 by Phinney et al. This study assessed the extent of weight loss in 12 women with obesity between the ages of 22-39 years assigned to diet-only or diet-plusAET groups [76]. The authors of this study concluded that "lean tissue preservation was excellent" for both groups (relative to the ratio present in Hemysfeld et al. 1990). However, it must be noted that their VLED variant was relatively high in dietary protein $(1.5 \mathrm{~g} / \mathrm{kg} /$ day $)$ [76].

Similarly, Pavlou et al. (1985) also performed an RCT in 72 men with obesity and an average age of 43.5 years over an 8-week period with AET and calisthenic training (rhythmic bodyweight exercises) as an addition to LED in the intervention group [77]. In this study, no statistical difference in LBM preservation was observed between the intervention and control groups [77].

Hunter et al. (2018) included a VLED and AET intervention arm in their study assessing the differential in response based on ethnicity, finding that the European-American and African-American women in this group both saw a reduction in LBM $\left(-0.09\right.$ versus $-0.10 \mathrm{~kg} / \mathrm{m}^{2}$, respectively) [73]. However, these outcomes were not statistically significant [73].

\section{High-Intensity Interval Training and LBM Retention in Low-Energy States}

High-intensity interval training (HIIT) is an exercise modality that, within the past two decades, has received attention in the literature due to its time-efficiency [78], the ability to maintain LBM [79] and similar cardiorespiratory and metabolic benefits as AET when initiated on a regular basis [80]. HIIT also appears to elicit skeletal muscle hypertrophy [81], an outcome that is traditionally associated with RET [82]. There are some suggestions that this adaptation is mediated through activation of the same mechanistic pathway (mTORC1) that is inferred to be responsible for skeletal muscle hypertrophy with RET [83].

HIIT has also demonstrated beneficial outcomes with respect to body composition adaptations. In a 2016 RCT, 17 women with obesity and an average age of $69 \pm 1$ years in neutral energy balance were assigned to either a HIIT or moderate-intensity continuous exercise (AET) group [84]. In this study, both the HIIT and AET groups exhibiting increases in LBM $(2.8 \pm 1.0 \%$ and $1.1 \pm 1.2 \%$, respectively), although neither group achieved statistical significance with this change in outcome [84]. However, the HIIT group exhibited superior losses in both visceral and abdominal fat $(-24.2 \pm 7.7 \%$ and $-8.3 \pm 2.2 \%$, respectively) [84].

Similarly, an investigation by Tremblay et al. (1994) sought to determine the impact that HIIT and AET have on skeletal muscle metabolism and on body fat [85]. Five men and five women between the ages of 18 to 32 years underwent a 15-week HIIT programme, whilst 
eight men and nine women took part in a 20-week AET programme [85]. At the end of the study, HIIT $\quad(56.1 \pm 31.5 \mathrm{~mm}$ vs. $47.4 \pm 25.2 \mathrm{~mm}$ ) resulted in a significantly larger reduction in subcutaneous trunk fat than in the AET group $(50.9 \pm 27.9 \mathrm{~mm}$ vs. $44.6 \pm 21.1 \mathrm{~mm}$ ) [85]. In addition, when corrected for energy balance, HIIT elicited a subcutaneous fat loss rate (per minute) that was approximately nine-fold larger [85].

Unfortunately, no studies assessing the potential effects of HIIT in the context of VLCD diets have been published to date, reflecting an area of further development in the scientific literature.

\section{Exercise Compliance in VLEDs}

Limited information currently exists concerning participant compliance with the addition of exercise to VLED. In a systematic review published in 2010, Weinheimer et al. attempted to assess the completion rate in AET only versus AET with VLED intervention strategies [68]. However, contradictory outcomes were reported between studies, with some showing a greater adherence in AET only while others favoured the combined intervention [68].

\section{EXERCISE-NUTRITION INTERACTIONS IN LEDS}

In the absence of energy restriction, the interaction between protein nutrition and RET has been shown to be key for maximising muscle anabolic responses. For example, supplemental protein during a RET programme results in a larger rate of LBM accumulation [86]. Acute studies have also demonstrated a two-fold increase in MPS response to protein feeding plus RET compared to a 1.5-fold increase in response to protein provision alone [87].

The role of protein supplementation-exercise interactions during VLED has had relatively little attention to date, but was investigated by Areta et al. in 2014 [88]. This study showed that the addition of acute RET and 15-30 g of whey protein increased MPS in men and women following 5 days of a LED of $125 \mathrm{~kJ}$ per $\mathrm{kg}$ of fatfree mass per day $(30 \mathrm{kcal}$ per $\mathrm{kg}$ of fat-free mass per day). Exercise alone returned the MPS rate to baseline and the ingestion of $30 \mathrm{~g}$ protein paired with exercise resulted in an MPS rate approximately 35\% above baseline [88]. Furthermore, it was determined that $30 \mathrm{~g}$ protein elicited approximately double the MPS rate response when combined with exercise compared with $15 \mathrm{~g}$ (16\%) [88].

The findings of Areta and colleagues are in accordance with the work of Pasiakos et al. (2013), who reported that an increase in protein intake (double $[1.6 \mathrm{~g} / \mathrm{kg} /$ day] or triple $[2.4 \mathrm{~g} /$ $\mathrm{kg} /$ day] the recommended daily allowance [RDA] $[0.8 \mathrm{~g} / \mathrm{kg} / \mathrm{day}])$ in a short-term LED state (-40\% maintenance intake) in combination with RET and AET resulted in preservation of LBM [89]. The authors noted that both doubleand triple-intake strategies elicited a similar degree of LBM retention [89].

These positive findings of Artea et al. and Pasiakos et al. were partially replicated by a 2018 systematic review and meta-analysis that included data from 49 studies. This review determined that additional LBM accretion in an energy neutral state is enhanced by additional protein supplementation, but only up to $1.6 \mathrm{~g} /$ $\mathrm{kg} /$ day [90]. Although the literature is suggestive of a LBM retention enhancement with protein nutrition in the context of VLEDs, further studies are required to both replicate these observed outcomes and investigate whether AET and/or HIIT exercise resembles the effect of RET when combined with additional protein supplementation in VLEDs. Elucidation of the above would provide clinicians with an evidence-based recommendation for patients preparing for VLEDs with respect to which form of adjunct exercise may potentially offset the recognised LBM reduction through this intervention.

\section{CONCLUSION}

Inconsistent evidence currently exists concerning the capacity for RET to serve as a retainer of LBM when applied concurrently with a VLED, with different studies demonstrating opposing 
Table 4 Current areas of uncertainty concerning the effects of protein supplementation and exercise in LBM retention during very-low-energy diets (VLEDs)

Do any corroborating data or evidence of replication exist concerning the findings of the Johansson et al. (2017) metaanalysis on protein supplementation and LBM retention?

In a controlled research setting and within a single study, what are the relative differences between LBM retention and skeletal muscle function when comparing RET, AET and HIIT?

Does the addition of protein supplementation in a VLED with exercise result in any statistically significant changes to any metabolic parameters post-intervention?

Does the incremental addition of protein supplementation in a VLED lead to any improvement in the degree of MPS in AET and HIIT?

Does variation in exercise modality during a VLED result in any difference in cardiopulmonary fitness, LBM retention, skeletal muscle function and metabolic parameters compared to one modality only?

Table 5 Areas of further research based on the established outcomes of this narrative review

Ascertainment of the LBM, muscle function and cardiopulmonary improvements in VLED diets between AET and HIIT

Determination of whether protein supplementation has a beneficial effect on LBM retention in sarcopenic individuals undergoing a VLED with AET, RET or HIIT exercise

Investigation of the differences in metabolic improvement $(s)$ between diabetic and non-diabetic patients receiving a VLED diet with AET or HIIT exercise

Further elucidation of the differential effects of ethnicity, age, biological sex and baseline LBM in the rate of LBM retention in patients receiving VLED diets, particularly with the addition of HIIT

Long-term studies (longer than 6 months) investigating the potential for adverse renal and bone metabolism pathology in VLED patients receiving protein supplementation

outcomes. Similarly, current evidence suggests that the addition of AET to a VLED demonstrates either an improvement in LBM retention or no difference compared to VLED-only interventions. The preliminary evidence concerning HIIT compared to AET is suggestive of an enhancement in fat mass losses in calorie-restricted states. However, no conclusive evidence currently exists concerning the interaction between HIIT and VLEDs. Further research is required to determine the benefits of additional protein supplementation during VLEDs when applied concurrently with exercise training, particularly modalities other than RET. Overall, a number of questions persist concerning the optimisation of VLED to improve LBM retention and other indicators of muscle physiology or other remarkable benefits (Table 4). Further investigation of these investigations and their potential benefits or drawbacks (Table 5) may form the basis for more secure clinical recommendations.

This article is based on previously conducted studies and does not contain any studies with human participants or animals performed by any of the authors.

\section{ACKNOWLEDGEMENTS}

Funding. Gratitude is extended to NP Pronk for providing a full copy of their study to our 
team. Dr. Ardavani received a fellowship grant from the UK Research Foundation, Novo Nordisk, UK. Our research group is supported by the Medical Research Council (MR/P021220/ 1, MR/K00414X/1) and Versus Arthritis (19891). No other funding was received for this study or publication of this article.

Authorship. All named authors meet the International Committee of Medical Journal Editors (ICMJE) criteria for authorship for this article, take responsibility for the integrity of the work as a whole, and have given their approval for this version to be published.

Authorship Contributions. Drafts completed by HA and AA. Senior reviews provided by BEP, KS, PJA and II.

Disclosures. Arash Ardavani, Hariz Aziz, Ken Smith, Philip J Atherton, Bethan E Phillips and Iskandar Idris have nothing to disclose.

Compliance with Ethics Guidelines. This article is based on previously conducted studies and does not contain any new studies with human participants or animals performed by any of the authors.

Data Availability. Data are available upon reasonable request.

Open Access. This article is licensed under a Creative Commons Attribution-NonCommercial 4.0 International License, which permits any non-commercial use, sharing, adaptation, distribution and reproduction in any medium or format, as long as you give appropriate credit to the original author(s) and the source, provide a link to the Creative Commons licence, and indicate if changes were made. The images or other third party material in this article are included in the article's Creative Commons licence, unless indicated otherwise in a credit line to the material. If material is not included in the article's Creative Commons licence and your intended use is not permitted by statutory regulation or exceeds the permitted use, you will need to obtain permission directly from the copyright holder. To view a copy of this licence, visit http://creativecommons.org/licenses/by$\mathrm{nc} / 4.0 /$.

\section{REFERENCES}

1. SCOOP. Reports on tasks for scientific cooperation. Collection of data on products intended for use in very-low-calorie-diets. 2002.

2. Saris WH. Very-low-calorie diets and sustained weight loss. Obes Res. 2001;9(Suppl 4):295S-301S.

3. Sellahewa L, Khan C, Lakkunarajah S, et al. A systematic review of evidence on the use of very low calorie diets in people with diabetes. Curr Diabetes Rev. 2017;13:35-46.

4. Chaston TB, Dixon JB, O'Brien PE. Changes in fatfree mass during significant weight loss: a systematic review. Int J Obes. 2007;31:743-50.

5. Garthe I, Raastad T, Refsnes PE, et al. Effect of two different weight-loss rates on body composition and strength and power-related performance in elite athletes. Int J Sport Nutr Exerc Metab. 2011;21: 97-4.

6. Brochu M, Malita MF, Messier V, et al. Resistance training does not contribute to improving the metabolic profile after a 6-month weight loss program in overweight and obese postmenopausal women. J Clin Endocrinol Metab. 2009;94:3226-33.

7. Krotkiewski M, Grimby G, Holm G, et al. Increased muscle dynamic endurance associated with weight reduction on a very-low-calorie diet. Am J Clin Nutr. 1990;51:321-30.

8. NICE. Obesity: identification, assessment and management. 2017. https://www.nice.org.uk/guid ance/cg189/chapter/1-Recommendations\#dietary. Accessed 16 Aug 2020.

9. Davies MJ, Alessio DAD, Fradkin J, et al. Management of hyperglycaemia in type 2 diabetes, 2018. A consensus report by the American Diabetes Association (ADA) and the European Association for the Study of Diabetes (EASD). Consens Rep Published Online First: 2018.

10. Dhindsa P, Scott A, Donnelly R. Metabolic and cardiovascular effects of very-low-calorie diet therapy in obese patients with Type 2 diabetes in secondary failure: outcomes after 1 year. Diabet Med. 2003;20:319-24.

11. Lean MEJ, Leslie WS, Barnes AC, et al. Primary careled weight management for remission of type 2 
diabetes (DiRECT): an open-label, cluster-randomised trial. Lancet. 2017;391:541-51.

12. Lean MEJ, Leslie WS, Barnes AC, Brosnahan N, Thom G, McCombie L, et al. Durability of a primary care-led weight-management intervention for remission of type 2 diabetes: 2-year results of the DiRECT open-label, cluster-randomised trial. Lancet Diabetes Endocrinol. 2019;7(5):344-55.

13. Sours HE, Frattali VP, Brand CD, et al. Sudden death associated with very low calorie weight reduction regimens. Am J Clin Nutr. 1981;34:453-61.

14. Janssen I, Heymsfield SB, Wang Z, et al. Skeletal muscle mass and distribution in 468 men and women aged 18-88 year. J Appl Physiol. 2014;89: 81-8.

15. Rudrappa SS, Wilkinson DJ, Greenhaff PL, et al. Human skeletal muscle disuse atrophy: effects on muscle protein synthesis, breakdown, and insulin resistance- $\mathrm{a}$ qualitative review. Front Physiol. 2016;7:361.

16. Bodine SC, Stitt TN, Gonzalez $\mathrm{M}$, et al. Akt/mTOR pathway is a crucial regulator of skeletal muscle hypertrophy and can prevent muscle atrophy in vivo. Nat Cell Biol. 2001;3:1014-9.

17. Gannon MC1, Nuttall FQ. Amino acid ingestion and glucose metabolism-a review. IUBMB Life. 2010;62(9):660-8.

18. de Boer MD, Selby A, Atherton P, Smith K, Seynnes OR, Maganaris CN, Maffulli N, Movin T, Narici MV, Rennie MJ. The temporal responses of protein synthesis, gene expression and cell signalling in human quadriceps muscle and patellar tendon to disuse. J Physiol. 2007;585:241-51.

19. Breen L, Stokes KA, Churchward-Venne TA, Moore DR, Baker SK, Smith K, Atherton PJ, Phillips SM. Two weeks of reduced activity decreases leg lean mass and induces "anabolic resistance" of myofibrillar protein synthesis in healthy elderly. J Clin Endocrinol Metab. 2013;98:2604-12.

20. Hunter GR, Plaisance EP, Carter SJ, Fisher G. Why intensity is not a bad word: optimizing health status at any age. Clin Nutr. 2018;37(1):56-60. doi: https://doi.org/10.1016/j.clnu.2017.02.004. Epub 2017 Feb 9. PMID: 28214041; PMCID: PMC5550361.

21. Ohanna M, Sobering AK, Lapointe T, et al. Atrophy of S6K1-/- skeletal muscle cells reveals distinct mTOR effectors for cell cycle and size control. Nat Cell Biol. 2005;7:286-94.

22. Drummond MJ, Fry CS, Glynn EL, et al. Rapamycin administration in humans blocks the contraction- induced increase in skeletal muscle protein synthesis. J Physiol. 2009;587:1535-46.

23. Jacinto E, Loewith R, Schmidt A, et al. Mammalian TOR complex 2 controls the actin cytoskeleton and is rapamycin insensitive. Nat Cell Biol. 2004;6: 1122-8.

24. Sarbassov DD, Ali SM, Sengupta S, et al. Prolonged rapamycin treatment inhibits mTORC2 assembly and Akt/PKB. Mol Cell. 2006;22:159-68.

25. Jewell JL, Guan K-L. Nutrient signaling to mTOR and cell growth. Trends Biochem Sci. 2013;38: 233-42.

26. Jung CH, Jun CB, Ro S-H, et al. ULK-Atg13-FIP200 Complexes Mediate mTOR signaling to the autophagy machinery. Mol Biol Cell. 2009;20:1992-2003.

27. Ganley IG, Lam DH, Wang J, et al. ULK1\{middle dot\}ATG13\{middle dot\}FIP200 complex mediates mTOR signaling and is essential for autophagy. J Biol Chem. 2009;284:12297-305.

28. Mitchell WK, Williams J, Atherton P, et al. Sarcopenia, dynapenia, and the impact of advancing age on human skeletal muscle size and strength; a quantitative review. Front Physiol. 2012;3:1-18.

29. Bodine SC, Latres E, Baumhueter S, et al. Identification of ubiquitin ligases required for skeletal muscle atrophy. Science. 2001;294:1704-8.

30. Lecker SH, Jagoe RT, Gilbert A, et al. Multiple types of skeletal muscle atrophy involve a common program of changes in gene expression. FASEB J. 2004;18:39-51.

31. Baehr LM, Furlow JD, Bodine SC. Muscle sparing in muscle RING finger 1 null mice: response to synthetic glucocorticoids. J Physiol J Physiol. 2011;58919:4759-76.

32. Sandri M, Sandri C, Gilbert A, et al. Foxo transcription factors induce the atrophy- related ubiquitin ligase atrogin-1 and cause skeletal muscle atrophy. Cell. 2004;117:1-2.

33. Stitt TN, Drujan D, Clarke BA, et al. The IGF-1/PI3K/ Akt pathway prevents expression of muscle atrophy-induced ubiquitin ligases by inhibiting FOXO transcription factors. Mol Cell. 2004;14:395-403.

34. Clausen $\mathrm{T}$. Regulation of active $\mathrm{Na}+-\mathrm{K}+$ transport in skeletal muscle. Physiol Rev. 1986;66:542-80.

35. Sinacore DR, Gulve EA. The role of skeletal muscle in glucose transport, glucose homeostasis, and insulin resistance: implications for physical therapy. Phys Ther. 1993;73:878-91. 
36. Straznicky NE, Lambert EA, Grima MT, et al. The effects of dietary weight loss with or without exercise training on liver enzymes in obese metabolic syndrome subjects. Diabetes Obes Metab. 2012;14: 139-48.

37. Rennie MJ, Wackerhage $H$, Spangenburg EE, et al. Control of the size of the human muscle mass. Annu Rev Physiol. 2004;66:799-828.

38. Baron AD, Brechtel G, Wallace P, et al. Rates and tissue sites of non-insulin- and insulin-mediated glucose uptake in humans. Am J Physiol. 1988;255: E769-74.

39. Bouzakri K, Koistinen HA, Zierath JR. Molecular mechanisms of skeletal muscle insulin resistance in type 2 diabetes. Curr Diabetes Rev. 2005;1:167-74.

40. Sayer AA, Syddall H, Martin H, et al. The developmental origins of sarcopenia. J Nutr Heal Aging. 2008;12:427.

41. Cruz-Jentoft AJ, Bahat G, Bauer J, et al. Sarcopenia: revised European consensus on definition and diagnosis. Age Ageing. 2019;48:16-31.

42. Westerterp-Plantenga MS, Lemmens SG, Westerterp KR. Dietary protein-its role in satiety, energetics, weight loss and health. Br J Nutr. 2012;108(suppl 2):S105-12.

43. NHS. Reference intakes explained. 2020. https:// www.nhs.uk/live-well/eat-well/what-are-referenceintakes-on-food-labels/. Accessed 14 Oct 2020.

44. Phillips SM, Van Loon LJC. Dietary protein for athletes: from requirements to optimum adaptation. J Sports Sci. 2011;29(Suppl 1):S29-38.

45. Reidy PT, Rasmussen BB. Role of ingested amino acids and protein in the promotion of resistance exercise-induced muscle protein anabolism. J Nutr. 2016;146(2):155-83.

46. Elena Volpi, Wayne W. Campbell, Johanna T. Dwyer, Mary Ann Johnson, Gordon L. Jensen, John E. Morley, Robert R. Wolfe. Is the optimal level of protein intake for older adults greater than the recommended dietary allowance? J Gerontol Ser A 2013;68(6): 677-681.

47. Morley JE, Argiles JM, Evans WJ, Bhasin S, Cella D, Deutz NE, Doehner W, Fearon KC, Ferrucci L, Hellerstein MK, Kalantar-Zadeh $\mathrm{K}$, Lochs $\mathrm{H}$, MacDonald N, Mulligan K, Muscaritoli M, Ponikowski P, Posthauer ME, Rossi Fanelli F, Schambelan M, Schols AM, Schuster MW, Anker SD; Society for sarcopenia, cachexia, and wasting disease. Nutritional recommendations for the management of sarcopenia. J Am Med Dir Assoc 2010;11(6): 391-6.
48. Il-Young Kim, Scott Schutzler, Amy Schrader, Horace Spencer, Patrick Kortebein, Nicolaas E. P. Deutz, Robert R. Wolfe, and Arny A. Ferrando. Quantity of dietary protein intake, but not pattern of intake, affects net protein balance primarily through differences in protein synthesis in older adults. Am J Physiol Endocrinol Metab 2015 308(1):E21-E28.

49. Paddon-Jones D, Rasmussen BB. Dietary protein recommendations and the prevention of sarcopenia. Curr Opin Clin Nutr Metab Care. 2009;12(1): 86-90.

50. Cuenca-Sánchez M, Navas-Carrillo D, OrenesPiñero E. Controversies surrounding high-protein diet intake: satiating effect and kidney and bone health. Adv Nutr. 2015;6(3):260-6.

51. Antonio J, Ellerbroek A, Silver T, et al. The effects of a high protein diet on indices of health and body composition-a crossover trial in resistance-trained men. J Int Soc Sports Nutr. 2016;13:3.

52. Long-Term Effects of High-Protein Diets on Renal Function. Anne-lise kamper and svend strandgaard. Annu Rev Nutr. 2017;37(1):347-69.

53. Esmeijer K, Geleijnse JM, de Fijter JW, Kromhout D, Hoogeveen EK. Dietary protein intake and kidney function decline after myocardial infarction: the Alpha Omega Cohort. Nephrol Dial Transp. 2020;35(1):106-15.

54. Delimaris I. Adverse effects associated with protein intake above the recommended dietary allowance for adults. 2013; 2013:126929

55. Willoughby D, Hewlings S, Kalman D. Body composition changes in weight loss: strategies and supplementation for maintaining lean body mass, a brief review. Nutrients. 2018. https://doi.org/10. 3390/nu10121876.

56. Barrows K, Snook JT. Effect of a high-protein, verylow-calorie diet on body composition and anthropometric parameters of obese middle-aged women. Am J Clin Nutr. 1987;45:381-90.

57. Longland TM, Oikawa SY, Mitchell CJ, et al. Higher compared with lower dietary protein during an energy deficit combined with intense exercise promotes greater lean mass gain and fat mass loss: a randomized trial. Am J Clin Nutr. 2016;103:738-46.

58. Larsen AE, Bibby BM, Hansen M. Effect of a whey protein supplement on preservation of fat free mass in overweight and obese individuals on an energy restricted very low caloric diet. Nutrients. 2018. https://doi.org/10.3390/nu10121918.

59. Johansson K, Neovius M, Hemmingsson E. Effects of anti-obesity drugs, diet, and exercise on weight- 
loss maintenance after a very-low-calorie diet or low-calorie diet: a systematic review and metaanalysis of randomized controlled trials. Am J Clin Nutr. 2014;99(1):14-23.

60. Zurlo F, Larson K, Bogardus C, Ravussin E. Skeletal muscle metabolism is a major determinant of resting energy expenditure. J Clin Invest. 1990;86(5): 1423-7.

61. Dasso NA. How is exercise different from physical activity? A concept analysis Nurs Forum. 2019;54(1):45-52. https://doi.org/10.1111/nuf. 12296 (Epub 2018 Oct 17 PMID: 30332516).

62. Knuiman P, Hopman MT, Mensink M. Glycogen availability and skeletal muscle adaptations with endurance and resistance exercise. Nutr Metab (Lond). 2015;21(12):59.

63. Ashutosh K, Methrotra K, Fragale-Jackson J. Effects of sustained weight loss and exercise on aerobic fitness in obese women. J Sports Med Phys Fit. 1997;37:252-7.

64. Burd N, Holwerda AM, Selby KC, et al. Resistance exercise volume affects myofibrillar protein synthesis and anabolic signalling molecule phosphorylation in young men. J Physiol. 2010;588: 3119-30.

65. Song Z, Moore DR, Hodson N, Ward C, Dent JR, O'Leary MF, et al. Resistance exercise initiates mechanistic target of rapamycin (mTOR) translocation and protein complex co-localisation in human skeletal muscle. Sci Rep. 2017;7(1):5028.

66. Carroll KM, Bazyler CD, Bernards JR, Taber CB, Stuart CA, DeWeese BH, et al. Skeletal muscle fiber adaptations following resistance training using repetition maximums or relative intensity. Sports (Basel). 2019. https://doi.org/10.3390/ sports7070169.

67. Kumar V, Atherton PJ, Selby A, Rankin D, Williams J, Smith K, et al. Muscle protein synthetic responses to exercise: effects of age, volume, and intensity. J Gerontol A Biol Sci Med Sci. 2012;67(11):1170-7.

68. Weinheimer EM, Sands LP, Campbellnure WW. A systematic review of the separate and combined effects of energy restriction and exercise on fat-free mass in middle-aged and older adults: Implications for sarcopenic obesity. Nutr Rev. 2010;68:375-88.

69. Bryner RW, Ullrich IH, Sauers J, et al. Effects of resistance vs aerobic training combined with an 800 calorie liquid diet on lean body mass and resting metabolic rate. J Am Coll Nutr. 1999;18:115-21.

70. Washburn RA, Szabo AN, Lambourne K, et al. Does the method of weight loss effect long-term changes in weight, body composition or chronic disease risk factors in overweight or obese adults? A systematic review. PLoS One. 2014;9:e109849.

71. Svendsen OL, Hassager C, Christiansen C. Six months' follow-up on exercise added to a shortterm diet in overweight postmenopausal women-effects on body composition, resting metabolic rate, cardiovascular risk factors and bone. Int J Obes Relat Metab Disord. 1994;18(10):692-8.

72. Donnelly JE, Sharp T, Houmard J, et al. Muscle hypertrophy with large-scale weight loss and resistance training. Am J Clin Nutr. 1993;58:561-5.

73. Hunter GR, Bryan DR, Borges JH, David Diggs M, Carter SJ. Racial differences in relative skeletal muscle mass loss during diet-induced weight loss in women. Obes (Silver Spring). 2018;26(8):1255-60. https://doi.org/10.1002/oby.22201.

74. Heymsfield SB, Casper K, Hearn J, et al. Rate of weight loss during underfeeding: relation to level of physical activity. Metabolism. 1989;38:215-23.

75. Hill JO, Sparling PB, Shields TW, et al. Effects of exercise and food restriction on body composition and metabolic rate in obese women 1-3. Am J Clin Nutr. 1987;46:622-30.

76. Phinney SD, LaGrange BM, O'Connell $\mathrm{M}$, et al. Effects of aerobic exercise on energy expenditure and nitrogen balance during very low calorie dieting. Metabolism. 1988;37:758-65.

77. Pavlou KN, Steffee WP, Lerman RH, et al. Effects of dieting and exercise on lean body mass, oxygen uptake, and strength. Med Sci Sports Exerc. 1985;17:466-71.

78. Roy M, Williams SM, Brown RC, Meredith-Jones $\mathrm{KA}$, Osborne $\mathrm{H}$, Jospe $\mathrm{M}$, et al. High-intensity interval training in the real world: outcomes from a 12 -month intervention in overweight adults. Med Sci Sports Exerc. 2018;50(9):1818-26.

79. Engelke S, Koch F, Sciascia Q. Exercise and muscle protein synthesis: not all roads lead to mTORC1. J Physiol. 2016;594(12):3179-80.

80. Milanović Z, Sporiš G, Weston M. Effectiveness of high-intensity interval training (HIT) and continuous endurance training for $\mathrm{VO}_{2 \max }$ improvements: a systematic review and meta-analysis of controlled trials. Sports Med. 2015;45(10):1469-81.

81. Blue MNM, Smith-Ryan AE, Trexler ET, et al. The effects of high intensity interval training on muscle size and quality in overweight and obese adults. J Sci Med Sport 2017;1-6. 
82. Berryman N, Mujika I, Bosquet L. Concurrent training for sports performance: the 2 sides of the medal. Int J Sports Physiol Perform. 2019;14(3): 279-85.

83. Pugh JK, Faulkner SH, Jackson AP, King JA, Nimmo MA. Acute molecular responses to concurrent resistance and high-intensity interval exercise in untrained skeletal muscle. Physiol Rep. 2015. https://doi.org/10.14814/phy2.12364.

84. Maillard F, Rousset S, Pereira B, et al. High-intensity interval training reduces abdominal fat mass in postmenopausal women with type 2 diabetes. Diabetes Metab. 2016;42:433-41.

85. Tremblay A, Simoneau JA, Bouchard C. Impact of exercise intensity on body fatness and skeletal muscle metabolism. Metabolism. 1994;43:814-8.

86. Frontera WR, Meredith $\mathrm{CN}, \mathrm{O}^{\prime}$ Reilly $\mathrm{KP}$, et al. Strength conditioning in older men: skeletal muscle hypertrophy and improved function. J Appl Physiol. 1988;64:1038-44.

87. Garrow JS, Summerbell CD. Meta-analysis: effect of exercise, with or without dieting, on the body composition of overweight subjects. Eur J Clin Nutr. 1995;49:1-10.

88. Areta JL, Burke LM, Camera DM, et al. Reduced resting skeletal muscle protein synthesis is rescued by resistance exercise and protein ingestion following short-term energy deficit. Am J Physiol Endocrinol Metab. 2014;306:E989-97.
89. Pasiakos SM, Cao JJ, Margolis LM, et al. Effects of high-protein diets on fat-free mass and muscle protein synthesis following weight loss: a randomized controlled trial. FASEB J. 2013;27:3837-47.

90. Morton RW, Murphy KT, McKellar SR, Schoenfeld BJ, Henselmans M, Helms E, et al. A systematic review, meta-analysis and meta-regression of the effect of protein supplementation on resistance training-induced gains in muscle mass and strength in healthy adults. Br J Sports Med. 2018;52(6): 376-84.

91. Gibson AA, Sainsbury A. Strategies to improve adherence to dietary weight loss interventions in research and real-world settings. Behav Sci (Basel). 2017. https://doi.org/10.3390/bs7030044.

92. Tsai AG, Wadden TA. The evolution of very-lowcalorie diets: an update and meta-analysis. Obes (Silver Spring). 2006;14(8):1283-93.

93. Festi D, Colecchia A, Orsini M, Sangermano A, Sottili S, Simoni P, et al. Gallbladder motility and gallstone formation in obese patients following very low calorie diets: use it (fat) to lose it (well). Int J Obes Relat Metab Disord. 1998;22(6):592-600.

94. Anderson JW, Hamilton CC, Brinkman-Kaplan V. Benefits and risks of an intensive very-low-calorie diet program for severe obesity. Am J Gastroenterol. 1992;87(1):6-15. 